\title{
"Interdisciplinary treatment approach for crown fracture of traumatized anterior teeth"- a case report
}

\author{
Dr. Ankita Singh ${ }^{1}$, Dr. Rajat Singh ${ }^{2}$, Dr. Rajul Vivek ${ }^{1}$, Dr. T.P. Chaturvedi ${ }^{3}$ \\ ${ }^{1,2}$ Department of Prosthodontics, Faculty of Dental Sciences, IMS, Banaras Hindu University, Varanasi, India. \\ ${ }^{3}$ Department of Orthodontics, Faculty of Dental Sciences, IMS, Banaras Hindu University, Varanasi, India
}

\begin{abstract}
Trauma to anterior teeth is common and requires accurate diagnosis and thorough treatment planning. The maxillary incisors are often affected during injury to the face because of their normal labial projection inflicting damage to the crowns. Multidisciplinary treatment approach is important for aesthetic and functional rehabilitation of anterior teeth with crown fracture. The purpose of this article is to present a case of fractured anterior teeth and its management taking in consideration the biologic, functional, esthetic and economic aspects.
\end{abstract}

Keywords- crown fracture, extrusion, orthodontic eruption, and trauma

\section{Introduction}

Facial injuries are more common in young patients as result of sports activities, falls, car accident, fight, and intentional assaults.[1] Maxillary incisors are more susceptible to get damaged by a blow on the face due to their labial projection. Crown fractures or crown- root fractures correspond to a significant part of such cases of tooth injuries. Crown fractures account for the majority of dental trauma in the permanent dentition (26$76 \%$ of dental injuries), while crown-root fractures represent only 0.3-5\%. [2-6] Depending upon the existence or not of pulpal involvement, they may be classified respectively as complicated, which are more frequent, or non-complicated root fracture. $[7,8]$

The literature reports several different treatment options of this kind of problem, ranging from preservation and use of fractured fragment as temporary or permanent crown, [9,10] orthodontic extrusion or surgical extrusion or a crown lengthening [1,9] to an extraction of the residual tooth followed by immediate or delayed implant surgery $[9,11,12]$ or fixed partial denture. [8]

The controlled orthodontic extrusion is also called as forced eruption, orthodontic eruption, vertical extrusion or assisted eruption. [14] First reported by Heithersay [15] and Ingber, [11] this vertical tooth movement can be obtained with removable or fixed orthodontic appliances, the former using mostly elastic bands or magnets [17,18-22] and fixed appliances and many modifications. Orthodontic extrusion may be utilized as highly satisfactory alternative to the surgical approach as the latter may lead to osseous and gingival contouring, exposing of cemento-enamel junction causing hypersensitivity and produce compromised esthetics. The present paper reports a case of complicated crown fracture in a young adult. The multidisciplinary treatment approach included endodontic treatment of the involved teeth followed by orthodontic extrusion and placement of definitive crown.

\section{Case Report}

A 24-year-old male patient reported to the department of prosthodontics, faculty of dental sciences, Institute of Medical Sciences, Banaras Hindu University, with a history of trauma in the upper anterior teeth due to a minor accident 24 hours back (Fig.1). Clinical examination revealed fracture in the coronal portion of maxillary right and left central incisors (Ellis Class III). [23] Further, radiographic diagnosis confirmed the presence of complicated fracture with pulpal involvement (Fig. 2).

Treatment was commenced with removal of fractured crown segment under local anesthesia. Root canal therapy was carried out immediately on both the central incisors. Definitive root canal treatment was performed thereafter with lateral condensation of gutta-percha points (Dentsply,Switzerland) and root canal sealer (Septodont, India) (Fig. 3). Prefabricated metal post (Parapost, Coltene/Whaledent, Switzerland) was selected and luted with Glass Ionomer Cement (GC Fuji I, USA) (Fig. 4, 5) followed by composite core (3M ESPE P60, USA) build-up after partial removal of gutta-percha points from the root canal in left and right central incisors, leaving $5 \mathrm{~mm}$ of the filling material at the apex for a good apical seal.

Orthodontic extrusion of right central incisor was implemented due to the absence of sufficient tooth structure for ferrule effect. Begg's brackets (D-tech Company,USA) were luted on labial surface of right central incisor as well as right and left lateral incisors (Fig. 6). Long e-chain (Libral Traders, USA) was used for the forced orthodontic extrusion (Fig. 7). Recall appointments at every 3 weeks for a total extrusion time period of 6 
months was followed. After the desired amount of orthodontic extrusion was achieved (Fig. 8), both maxillary central incisors were successfully restored with metal-ceramic restorations (Fig. 9,10).

\section{Discussion}

Management of traumatic injuries and their consequences can be challenging and therefore a treatment option providing aesthetic, functional and economical solution to the clinical problem should be preferred. Interdisciplinary approach involving oral surgery, endodontics, orthodontics and prosthodontics has been a recognized treatment option for functional and aesthetic success of complicated crown-root fracture.

Extraction must not be the first choice of treatment for the fractured and badly broken down young permanent teeth in the anterior region and alterative treatment modalities must be considered. [24] Different treatment strategies have been proposed for cases of complicated crown-root fracture including surgical exposure of the fractured surface, orthodontic or surgical extrusion of the apical fragment, intentional replantation and tooth extraction in more severe cases. [25] Treatment option for any pulp exposure reported after 72 hours requires extirpation of infected pulp therefore, removal of infected fractured crown segment followed by root canal therapy was initiated in the present case. Extrusion was method of choice for crown lengthening due to lack of residual tooth structure for an adequate ferrule. The use of orthodontic extrusion, also referred to as forced eruption, has been suggested as an alternative to periodontal crown lengthening which involve the removal of supporting alveolar bone and can compromise esthetics. [26]

\section{Conclusion}

Multidisciplinary approach has been recognized and established as a key factor for successful outcomes in dental problems. Orthodontic extrusion in fractured anterior teeth is a simple procedure that has been used for stable and predictable results in the process of prosthetic rehabilitation of such cases at low cost and requires minimal specialized materials and orthodontic skills.

\section{References}

[1] G. Holan, Y. Shmuli, Knowledge of physicians in hospital emergency rooms in Israel on their role in cases of avulsion of permanent incisors, Int J Paediatr Dent, 2003;13:13-19

[2] F.M. Andreasen, J.O. Andreasen, editors. Crown fractures. Textbook and color atlas of traumatic injuries to the teeth, 3rd edn. Copenhagen: Munksgaard;1994,19-56

[3] J.O. Andreasen, F.M. Andreasen, Crown-root fractures. Textbook and color atlas of traumatic injuries to the teeth, 3rd edn. Copenhagen: Munksgaard; 1994, 257-77.

[4] M. Zerfowski, A. Bremerich, Facial trauma in children and adolescents, Clin Oral Invest 1998;2:120-4

[5] S. Wilson, G.A. Smith, J. Preisch, P.S. Casamassimo, Epidemiology of dental trauma treated in an urban pediatric emergency department, Pediatr Emerg Care 1997;13 (1):12-5.

[6] J.P. Delattre, F. Resmond-Richard, C.Allanche, M. Perrin, J.F. Michel, A. Le Berre, Dental injuries among school lchildren aged from 6 to 15, in Rennes (France). Endod Dent Traumatol 1994;11:186-8.

[7] J.C.M. Castro, W.R. Poi, T.M. Manfrin, L.G. Zina, Analysis of the crown fractures and crown- root fractures due to dental trauma assisted by the Integrated Clinic from 1992 to 2002, Dent Traumatol 2005;21:121-6.

[8] F.M. Andreasen, Reattachment of subgingivally fractured central incisor with an open apex, Dent Traumatol 2007;23:263-4.

[9] C. Villat, P. Machtou, C.Naulin Ifi. Multidisciplinary approach to the immediate esthetic repair and long-term treatment of an oblique crown-root fracture, Dent Traumatol 2004;20:56-60

[10] E. Koparal, T.Ilgenli, Reattachment of a subgingivally fractured central incisor root fragment : report of a case, J Clin Pediatr Dent 1999;23:99-104

[11] R.D. Trushkowsky, Esthetic, biologic and restorative considerations in coronal segment reattachment for fractured tooth: a clinical report. J Prosthet Dent 1998;8:139-43

[12] RLRG. Leroy, JKM. Asp, FM. Raes, LC. Martens, JA. De Boever, A multidisciplinary treatment approach to a complicated maxillary dental trauma: a case report, Endod Dent Traumatol 2000;16:138-42.

[13] JC. Meiers, MA. Freilich, Chairside prefabricated fiber reinforced resin composite fixed partial dentures, Quintessence Int 2001;32:99-104.

[14] LJ. Oesterle, LW. Wood, Raising the root. A look atorthodontic extrusion, JADA 1991;122:193-8.

[15] GS. Heithersay, Combined endodontic-orthodontic treatment of transverse root fractures in the region of the alveolar crest, Oral Surg 1973;36:404-15.

[16] JS. Ingber, Forced eruption. A method of treating nonrestoreable teeth-periodontal and restorative considerations, $J$ Periodontol 1976;47:203-16.

[17] A. Fournier, Orthodontic management of subgingivally fractured teeth, J Practical Orthod 1981; July:502

[18] L. Bondemark, J. Kurol, AL. Hallonsten, JO. Andreasen, Attractive magnets for orthodontic extrusion of crown-root fractured teeth, Am J Orthod Dentofac Orthop 1997;112:187-93.

[19] MS. Cooke, B. Scheer, Extrusion of fractured teeth - the evolution of practical clinical techniques, Brit Dent J 1980;149:50-53.

[20] EJ. Hovland, Horizontal root fractures. Treatment and repair, Dent Clin North Am 1992;36:509-25.

[21] I. Kocadereli, F. Tasman, SB. Guner, Combined endodontic orthodontic and prosthodontic treatment of fractured teeth, Case report. Aus Dent J 1998;43:28-31.

[22] RC. Mandel, WC. Binzer, JA.Withers, Forced eruption in restoring severely fractured teeth using removable orthodontic appliances, J Prosthet Dent 1982;47:269-74.

[23] RG.Ellis, The classification and treatment of injuries to the teeth of children. 5th edn. Chicago: Year Book Medical Publishers, 1970:56-199. 
[24] Frank Spear, A patient with a central incisor fractured apically in relation to the gingival margin, J Am Dent Asso. vol.140, no. 3, 3ss-399

[25] Saito et al, Management of a complicated crown-root facture using adhesive fragment reattachment and orthodontic extrusion, Dent Traumatol 2009;25:541-544

[26] Ilken Kocadereli, Fugen Ta, Sman Ba, Shan Guner, Combined endodontic-orthodontic and prosthodontic treatment of fractured teeth-Case report, Dent Update. 2009;36(4): 212-4, 217-8

\section{FIGURES}

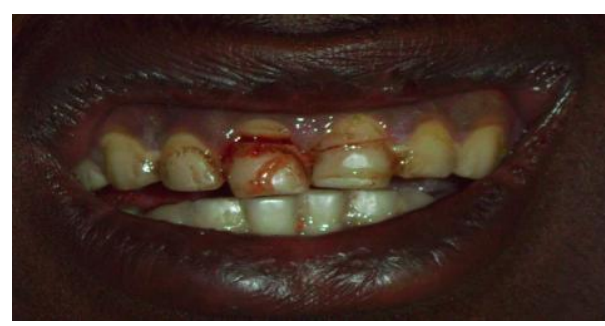

Figure 1- pre-operative intraoral view

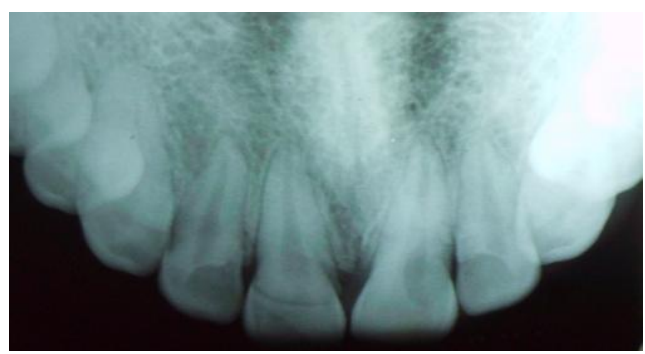

Figure 2- diagnostic radiograph

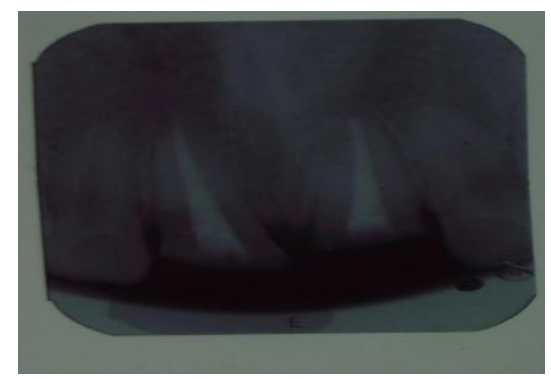

Figure 3- post-obturation radiograph

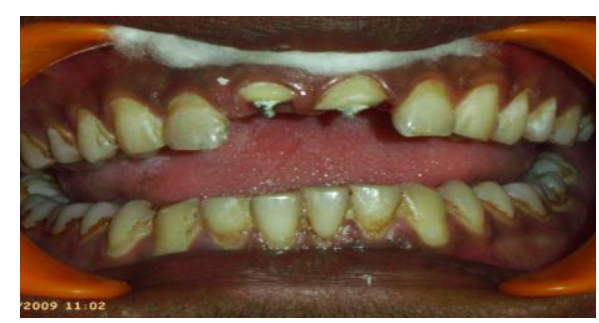

Figure 4- clinical view after post placement

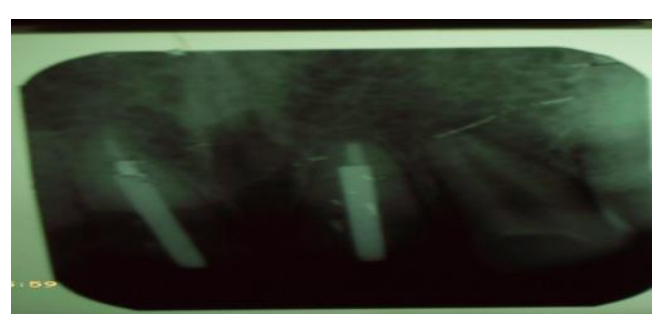

Figure 5- radiographic view after post placement 


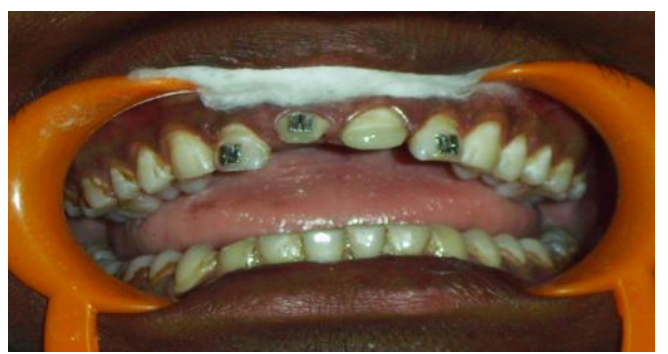

Figure 6- clinical view with luted begg's brackets

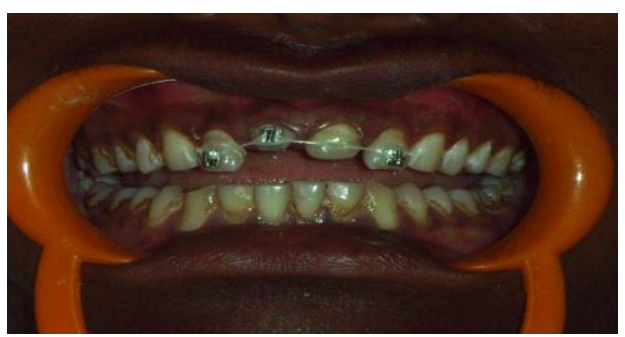

Figure 7- e-chain placed for application of force by orthodontic extrusion

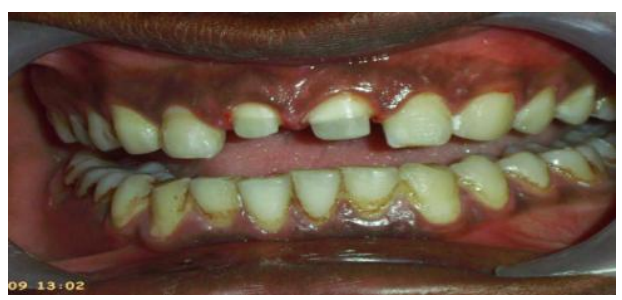

Figure 8- post orthodontic extrusion- intraoral view

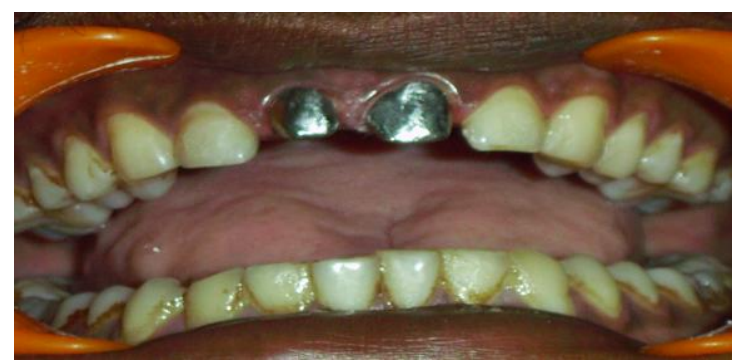

Figure 9- metal try-in

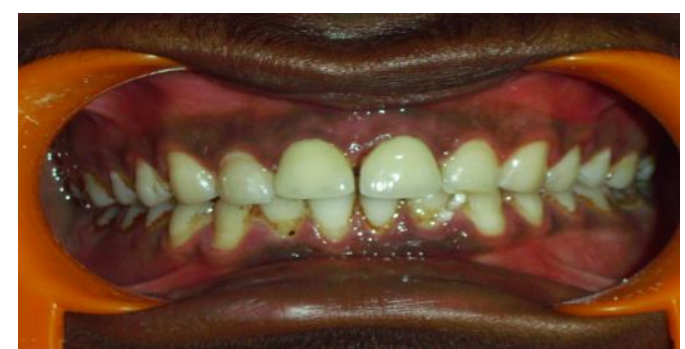

Figure 10- postoperative intraoral view after definitive crown placement 